\title{
浅析互联网在家校共育中的有效应用
}

米飞娥

陕西省榆林市第二十四小学

DOI:10.32629/er.v3i1.2368

[摘要] 随着互联网、大数据、云计算等技术的发展, 家校共育方式也正进行着一场巨变, QQ 、微信、家校合作平台 APP 等现代网络应用系统 和软件,为家校共育带来了新的契机。

[关键词] 互联网; 家校共育; 有效应用

\section{1 互联网时代下家校共育的研究价值和研究意义}

通过与互联网结合, 进行家校共育目标的构建, 丰富了现代教学的方 式和理念, 促进了教学理论的纵向发展, 增加了教学模式的深度和广度。同 时, 运用互联网的优势开展家校合作, 打造家校共育的目标, 对内可以加强 对学生的管理, 对外可以加强与家庭的沟通, 不仅可以营造良好的学习和 教育氛围, 激发学生学习兴趣, 还可以通过网络平台对家长进行培训, 发挥 家庭教育的巨大作用, 提高教学效果, 强化教育作用。

\section{2 互联网在家校共育中应用策略}

2. 1 创建家校交流平台, 借助微信、QQ平台实施家校共育

由于社交软件的开放和自由, 使得在此平台上, 不仅可以教师与家长 间交流, 更能促进家长间的交流与信息共享, 分享各自的教育经验。利用班 级QQ平台进行家校共育: 这种网络下的交流环境打破了家校互动的时空界 限。由于大部分家长工作繁忙, 与教师交流的时间, 空间有限, 但他们中大 部分使用智能手机和电脑。我们可以在QQ群里留言, 交流教育学生的经验, 家长也可以在群里分享一些好的方法, 实现了真正的零距离互通。利用班 级微信群进行家校共育, 微信已成为我们日常生活不可少的一种交流方式, 我们除了在微信上与家长沟通之外, 还可以将自己的一些教育学生的好文 章, 好方法, 可以发布在微信上, 还可以分享到家校朋友圈中或发送给个别 家长, 以对他在教育孩子方面提供必要的帮助。教师通过 “班级家校共育 (微信、QQ) 群” 密切和家长的沟通。及时与家长分享学生活动的精彩瞬间, 有效引导家长们积极参与家校共育。鼓励家长随时随地通过班级群了解学 生实时情况, 及时与教师沟通, 共同分享家校共育心得。

2. 2 组织教师和家长的网络培训, 改变教学观念

随着社会的进步、科技的发展, 传统的教育模式也不再适应如今的教 学, 而在学校采用新型教育方式的同时, 家长还不了解, 在家庭教育中仍然 采用传统的错误的方式。如一些家长会对孩子说 “你好好学习, 进步了就 给你奖励”等话, 这样虽然在短时间内提高了学生的学习成绩, 但却影响了 孩子的学习兴趣和学习态度, 形成了错误的学习观念, 忽略了学习的重要 性, 我学习就是为了得到奖励。这样就造成了教育的脱节, 所以家庭教育作 为学生教育中重要的一部分, 学校有必要对家长开展相应的网络培训, 接 受教师的学习指导, 学习新型的教育方式, 树立正确的教学观念, 了解有效 的家庭教育, 形成教育合力, 共同解决学习过程中遇到的学习问题和心理 问题。例如, 对于学习成绩差、学习态度不端正、自尊心强、逆反心理严 重的学生, 教师可以通过网络平台对家长进行指导, 可以推荐家长阅读关 于教育的书籍, 观看关于教育的讲座, 教授正确的教育方式, 建议家长多与 孩子沟通、交流, 多开展旅游等家庭活动, 拉近家长与孩子的距离, 舒缓孩 子的学习压力, 了解孩子的心理, 从而方便以后的教育方向和及时地引导。 家长也要避免对孩子直接批评, 而要从孩子角度多考虑, 发现孩子身上的 优点和特长进行鼓励, 多方向, 多角度的培养孩子的兴趣, 从而改善孩子对
学习的抵触心理。对于教师的网络培训, 学校主要安排业余时间加强教师 对互联网下家校共育理论的理解和学习, 充分了解到家校共育对学校教育 的积极意义, 学习相关措施, 提高专业素养, 促进家校共育目标的发展。

2. 3改善管理任务流程, 助推家校网络共育稳步前进

基于管理组织网络的流程, 学校应当考虑怎样针对学生个人成长空间 的创建环节展开活动。家庭与学校不但可以借助学生个体的成长空间这一 信息平台, 定位且实现学生的成长需求, 而且还能够通过利用部分教育举 措, 有效提高学生的认知水平, 完善其成长追求。由此, 教师可由点及面, 逐步形成信息化背景下家校互动模式的实践形态。另外, 按照学生在各个 阶段的发展需要, 学校应依据先后顺序调整课程设置、社会实践资源开发、 师资配置以及资金预算等任务, 使校内各职能部门在管理层面予以整合, 从呈现点状无序状态过渡成以点带面、整体有序地进行活动, 优化学校管 理的内涵品质, 创新不同维度和系列的 “互联网+” 家校共育工作机制: 在教师操作层面建立主题议事培训制; 在学生实践层面构建调研访谈跟进 制以及学生问题干预制; 在家校合作层面上建构家校互动共育制或者家庭 幸福跟踪制等。还需要在若干系列的体制中设计实施流程。此外, 还可利 用问题反馈单, 来推进引导和指挥项目。这份反馈单为小学校长统一领导 整合各教育职能部门的任务提供了信息, 为完善与升级网络平台提供了便 利, 更为家长和教师提供了可借鉴的经验。

2. 4 远程互动, 共享资源

为打破德育课堂教学的时空界限, 学校应研究将信息技术和德育课程 进行有效整合的方法。教师可运用网络进行家校远程互动, 共享教学资源, 实现家校共育, 取得共赢。每逢节假日, 教师可以通过微博与学生远程互动, 师生之间可以进行远程交流。教师还可以开发家长资源, 让家长参与课程 互动, 形成家校合作, 开展多方面的德育活动。教师可在微博平台上布置假 日实践作业, 通过远程互动, 随时随地进行家校德育互动, 使学生的德育活 动更具开放性和实效性。例如, 清明节时, 教师可在微博开设 “清明祭英烈” 话题, 布置德育作业, 让学生参加学校的祭英烈活动, 然后看一篇英雄事迹, 再写一篇读后感, 写英雄的优秀品格及精神, 写在这位英雄身上学到了什 么, 在以后的生活中应该怎么做。学生们纷纷在微博上写道: 他坚持不解 的精神震撼了我, 我觉得自己如果努力学习英语应该可以学得很好, 不应 该看见英语就退却; 看了他的事迹后我瞬间醒悟, 知识是无限的, 我不应该 因为现在的成绩而自傲、自以为是, 要知道虚心使人进步。同时, 家长可以 对学生的话题做出评价, 家长不仅可以了解学生的思想情况, 还能参与到 学生的德育实践活动中。家长还可以在微博上与教师和其他家长进行互动, 交流一些教育成果, 相互学习, 相互分享。

2.5创设家校共育的网络讲堂, 建构表彰奖励制度体系

互联网家校共育讲堂的建立, 有助于引领家长树立正确的教育观。将 现阶段先进的教育观念及系统方法全部展现给家长, 为家校共育提供有效 


\title{
汉英翻译中比喻的翻译研究一一张培基《英译中国现代散文选》 为例
}

\author{
朱蕾 \\ 江西财经大学外国语学院 \\ DOI:10.32629/er.v3i1.2387
}

[摘 要] 比喻作为一种重要的修辞手法,在汉语中的使用由来已久。比喻赋予语言以灵气和色彩,给读者留有想象、体会的空间。进行汉英翻 译时,译者需要兼顾汉语比喻内涵和英语表达习惯。本文以张培基《英译中国现代散文选》为例,总结了不同类型的比喻的翻译策略及方法 [关键词] 比喻; 直译; 意译; 译文读者

张培基《英译中国现代散文选》精选中国现代散文名篇进行翻译, 出 版以来受到众多学子、学者的推崇, 也为汉英翻译研究提供了丰富的素材。 比喻是一种将两个不同事物由某一相似点联系在一起的修辞手法。比喻让 语言产生了联想意义, 让语言更加鲜活、形象、生动, 增强了表达效果。各 种巧妙的比喻丰富了语言的内涵, 也进一步丰富了语言文化。比喻的英译 可根据不同情况采用不同的翻译策略及方法, 张培基《英译中国现代散文 选》中涉及众多比喻的巧妙英译, 值得深入研究、学习和借鉴。

\section{1 比喻的认知}

1. 1 比喻的特征

比喻主要由本体 (喻体所依附的对象) 和喻体 (形容本体的术语) 组成。 比喻在词语旧义的基础上创造出新义, 新义与旧义往往互相联系、存在相 似性。另外, 比喻是一种语言使用现象, 需要结合特定语境进行分析。单独 的词不能构成比喻, 也不具有分析的价值。

\section{2 比喻的功能}

比喻的使用丰富了语言的多样性, 增强了语言的魅力。比喻的功能主 要有以下几点: (1) 比喻让表达更加生动且富有感染力, 并引起读者的联想 与想象, 让人印象深刻; (2) 比喻能化抽象为具体, 增强语言的直观性, 让人 在已有的主观经验的基础上理解没有经历过或看到过的事物; (3) 比喻可 以用简洁的语言表达某些复杂或难以明言的思想, 化深奥为浅显, 增加语 言的易懂性。

\section{2 比喻的翻译策略及方法}

2.1 以源语为导向的翻译

以源语为导向的翻译遵循异化的翻译策略, 让读者向作者靠拢。比喻 的异化翻译有助于保存源语的风格特色, 体现文化内涵。比喻的异化翻译 往往采取直译手法, 取其喻意进行翻译, 保留了原文本的修辞效果。

人类具有共有的非文化知识, 即不同民族的非相互习得的知识以及某

的理论指引与技术支撑, 努力为家校共育提供更加丰富饱满的精神食粮, 合理引领家校共育和谐有序发展。每学年学校可评选一批家校共育模范家 庭, 予以表彰, 这样可以充分发挥榜样的力量, 带领全部家长全力以赴投入 家校共育的工作中

\section{6 建立网上 “家校共育讲堂”}

学校借助校园网和学校网站, 建立网上 “家校共育讲堂”, 和家校共育 专栏, 将优秀的家庭教育讲座推荐给家长, 在专栏上发送有关家庭教育的 文章, 把当前先进的教育理念、方法系统性地呈现给家长, 为学生家校共育 提供科学的理论指导, 促进家校共育的健康发展。

3 结束语
些认知过程是相似的。汉语中有些比喻在英语中有相似的含义, 或能带来 相似的体验或感受, 采用直译法不但不会影响译文读者的理解, 还能保留 原比喻的形式特色和修辞效果。如:

例1：骆驼的峰就是一座拱桥, 它沟通了东方和西方的文化….... ${ }^{[1]}$

译文: The camel's hump symbolizes an arch bridge linking up the cultures of East and West. ${ }^{[2]}$

“桥”此处指的是一种“纽带”, 《牛津高阶英汉双解词典》对“bridge” 一词有着近乎相同的定义 “a thing that provides a connection or contact between two different things”。汉译英时, 重现这类比喻意象 丝毫不会影响译文读者对译文的理解。

例2: 巷, 是城市建筑艺术中一篇飘逸恬静的散文, 一幅古雅冲淡的图画。 ${ }^{[3}$

译文: The lane, in terms of the art of urban architecture, is like a piece of prose of gentle gracefulness or a painting of classic elegance and simplicity.

无论是在中国还是在西方国家，“散文”和 “图画” 都能带给人以美 的体验和享受, 译文读者可在这种固有的思维基础上进行理解。由于人类 对这类事物的感知是相同或相似的, 直译不会造成语言上的障碍, 译文读 者稍加联想即可感知原作意境。

有些文学作品中运用意象的罗列来表达浓烈的情感或增强语言的表 现力与审美情趣。文学翻译注重翻译的文学性, 译文应尽量再现原作艺术、 意境, 给读者以近似于阅读原文的美的感受。

例3: 比起北国的秋来, 正像是黄酒之与白干, 稀饭之与馍馍, 鲇鱼之与 大蟹, 黄犬之与骆驼。

译文: Southern autumn is to Northern autumn what yellow rice wine is to kaoliang wine, congee to steamed buns, perches to crabs, yellow dogs to camels.

总之, 在互联网的环境条件下, 搭建家庭与学校之间全程、全员及全方 位育人的立交桥, 使交流更为畅通高效, 使家庭与学校的关系更加和谐, 是 促进家校共创与教育健康发展的新颖平台。

[参考文献]

[1]黄盈.浅析初中语文教学中的多元化教学方法 [J].小作家选 刊,2015(26):146-147.

[2]刘荣信.对初中语文教学中的多元化教学方法探究 [J]. 课外语 文,2015(24):119.

[3]胡强.多元化教学策略在初中语文教学中的有效实施策略探究 [J]. 文理导航(上旬),2015(04):4-5 